\title{
Media Ownership and Bias: Evidence by the Washington Post's Reporting after Amazon's Acquisition in 2013
}

\author{
Tongyi Jin ${ }^{1^{*}}$, Altynay Abilgaziyeva ${ }^{2}$, Tsz Ting Lam ${ }^{3}$ \\ ${ }^{1}$ Department of Applied Social Sciences, The Hong Kong Polytechnic University \\ ${ }^{2}$ Ernst \& Young \\ ${ }^{3}$ RSM Hong Kong \\ Email: serena-tongyi.jin@polyu.edu.hk
}

\begin{abstract}
This study examines the impact of ownership change on media coverage by investigating the impact of Jeff Bezos's (Amazon's owner) purchase of the Washington Post (WP) in October 2013. We collect all articles that have Amazon mentions published by WP and the New York Times (NYT) for 12 months before and 12 months after the acquisition. Then, we use the difference-in-differences method to compare changes in sentiment, length, and time of publication of the articles reported by WP compared to NYT. From the comparison, we show that Amazon's acquisition has posed a certain extent of influence on the publication time of the articles. Our findings highlight that ownership change limits the media's ability to fulfill its role as a watchdog without interference.
\end{abstract}

Keywords: media ownership, bias, acquisitions

\section{Introduction}

"Most of what you have read or watched in the media is true and $100 \%$ accurate. But HOW you are told the stories, and When, there lies the manipulation!" (Kanjo, 2016). ${ }^{[1]}$ We often receive different information from the media, but how these media deliver the story could preemptively affect how we comprehend the event. Media might attempt to predetermine our perception of a subject with labels, omissions and frame of the news by packaging them with a tone, exposure and other effects. "The press itself is a facility and falsely labeled "the liberal media" by the hundred of conservative columnists, commentators, and talk show hosts who crowd the communication universe while claiming to be shut out of it." (Parenti, 1997)..$^{[2]}$

In our research, we focus on a particular event - Amazon's purchase of the Washington Post in October 2013 to identify how the change in ownership shapes the media coverage. Right after acquisition, new owner, Jeff Bezos, encouraged WP's shift of focus from "For and about Washington" to becoming a "global" company and encouraged WP to cover both him and Amazon aggressively (Meyer, 2014). ${ }^{[3]}$ Bezos intended to expand the national and worldwide audience, and he started a massive digital transformation at WP and aggressively hired new people to spread them across new projects. Although it is stated that Bezos has focused on technology, not journalism ("Exploring the Amazon", 2015) ${ }^{[4]}$, from the following example, it is clear that on average the coverage of WP owned by Bezos has changed to be more beneficial towards Amazon.

The recent Amazon-related news that caught a lot of media attention was the shocking divorce of Jeff Bezos with his former wife (Day \& Metcalf, 2019) ${ }^{[5]}$ The news articles about the divorce extracted from Factiva showed that there is an evident variation of tone between different media. For instance, the number of articles issued by the New York Times is nine times more than that by WP with the average length of articles being 243 words longer than WP. It may represent WP's desire not to emphasize the news because a divorce is a negative event for Amazon's stock price, i.e. it might worry investors about the control stability. Meanwhile, NYT framed shareholders' concerns in one of the headlines (Stewart, 2019). ${ }^{[6]}$ After the divorce was finalized, WP published an article that emphasized Bezos retaining $75 \%$ of the couple's stock and ALL voting power in order to stabilize the market ("Jeff Bezos, in divorce", 2019). ${ }^{[7]}$ When the National Enquirer published text messages between Bezos and a woman he was having an affair with, WP produced a rather lengthy article (2782 words), accusing National Enquirer in blackmail and defending Bezos ("Inquiring minds", 2019). ${ }^{[8]}$ From these, we assume that WP has been acting as Bezos' mouthpiece after the acquisition. Hence, we find it interesting to study how biased WP became in reporting Amazon related news after the acquisition.

In this paper, we contributed to the existing literature by assessing the media's difference across three important metrics - length, sentiment, and publication time of articles before and after the ownership change compared to its competitors. We introduced a new tool, a natural language processing technique, to measure the sentiment score of the 
articles. By analyzing the differences in sentiment, length, and publication time of the articles, we could identify the bias in media coverage. Hence, it is evident that the new owner could achieve various goals by using his power to control news published.

\section{Literature Review}

Media's essential role in a democratic society is to act as a watchdog of the public and hold the actions of the government, political leaders, and business elites accountable. The free flow of ideas is critical to ensure the wellfunctioning of society (Archer \& Clinton, 2018). ${ }^{[9]}$ However, nowadays, with six corporations controlling almost $90 \%$ of the media in the USA (Lutz, 2012) ${ }^{[10]}$, there is increasing pressure on the media's true motivations. That is, owners of the large conglomerates, taking more control over mass media in the USA, have incentives to report profit-maximizing news. The importance of media as an information intermediary that enables citizens to make well-thought choices and critical evaluations has shifted towards turning to a platform for owners to exercise their business interests and influence the public.

Plenty of prior literature explores the consequences of ownership change to media tycoons, moguls, or public organizations such as political parties, the state, and multinational corporations. For instance, a study conducted by Chomsky (2006) illustrated how media ownership limits the media's capacity to perform its so-called watchdog role in society without any interference. ${ }^{[1]}$ His study is based on the memoirs written by Turner Catledge in 1971, the top editor at the NYT. In his memoirs, Turner Catledge revealed that Arthus Hays, NYT owner, has written more than 400 memos with instructions, suggestions, complaints, and orders regarding the news published. Such ownership intervention was regarded as usual practice, and Catledge would remove the owner's name from the memo and suggest his ideas as his own, or as ideas of an "interested reader". Almost in all cases, the owner's suggestions were met, and even in cases when the owner's ideas were not newsworthy, the stories would still appear in the newspaper. Careful observations of internal interactions showed that the owner presented no self-consciousness about interference and the reporter never questioned the owner's right to interfere while deciding the news content.

We can see further evidence on how ownership frames the coverage from research done by Archer \& Clinton (2018). ${ }^{[9]}$ On August 1, 2007, Rupert Murdoch purchased the Wall Street Journal (WSJ), being drawn to its status of the top-selling US daily newspaper. With the incentive to further increase the profitability, Murdoch changed the WSJ's coverage to include more political stories to increase media profitability. Archer and Clinton studied the impact of Murdoch's purchase on the WSJ's coverage. They examined the percentage change in political stories coverage across different newspapers, such as NYT, WP, and USA Today. As a result, they found that the post-acquisition change in the WSJ's political coverage is remarkable, especially in the front-page stories. Furthermore, Archer and Clinton identified that the WSJ's coverage became more conservative, which reflects the political views of Murdoch, who is republican himself. In the past, Murdoch used other media outlets in his control to restrict publishing positive articles on the UK entering the Eurozone (Harding, 2002) ${ }^{[12]}$, and to influence public opinion on the Iraq War (Szalai, 2007) ${ }^{[13]}$.

In addition, anecdotal evidence concerning the significance of the media owners controlling the accent or coverage of events in the news is bountiful. One of the specific examples of media coverage being influenced by the owner's interest happened in 1980 when the Los Angeles Times did not report US\$ 2 billion tax-paid water projects in California, beneficial to the Times-Mirror Company (the owner of LAT). In contrast, NYT and the Bakersfield Californian chose the event as appropriate enough to cover (Bagdikian, 1992). ${ }^{[14]}$ Another example includes the Telecommunications Act of 1996 when the newspapers that benefited from the new act, in their coverage reported more positively on the proposed changes. In contrast, newspapers that did not gain anything reported more negatively with negative consequences appearing three times more (Gilens and Hertzman, 2000). ${ }^{[15]}$

Hanretty (2014) suggested that different types of media ownership have different consequences on media coverage as particular owners such as political parties, media tycoons, moguls, etc. have distinct goals to achieve. ${ }^{[16]}$ The ownership by conglomerates implies active self-promotion in the media. For instance, when Warner Communications acquired Time magazine in 1989, the magazine which was in recession before, was transformed into an exclusive platform to exercise the conglomerate's promotion and entertainment possibilities (Turow, 1994). ${ }^{[17]}$ In our research, we assume that Jeff Bezos acquired the Washington Post, which also was in recession before the acquisition, to turn it to the platform to exercise promotion opportunities. Thus, we expect aggressive coverage of Amazon-related events by the Washington Post after the acquisition.

The media outlets utilize different types of media bias to achieve their goals. For instance, when Butler \& Gurun (2012) studied the bias of the local newspapers in reporting local firms compared to non-local companies, they identified 
that reports on local companies contain fewer negative words compared to non-local companies. ${ }^{[18]}$ The reason behind such favoritism was due to the local companies being the source of advertising income for the local newspapers. Media bias is shown to affect the public opinion even when the rational reader understands the bias of the media outlet. Because the public never knows how much information the media has, the media may present the contrary information more powerfully, tilt the selection of words, and use other ways to influence the public's perception (Anderson \& McLaren, 2012). ${ }^{[19]}$

The research conducted by Hamborg, Donnay, and Gipp (2019) provides insights on how to measure different types of media bias. ${ }^{[20]}$ This study combines computer science and social science approaches to study media bias and identifies the systematic way of testing it. They defined media bias as three types: selection, coverage, and presentation. The selection bias, concerning stories media selected for reporting. Coverage bias is related to the transparency of entities or topics in media coverage. Presentation bias is related to the way that news is reported. In our research, we aim to explore the impact of the Amazon acquisition on WP's reporting of Amazon-related news. Our study aims to contribute to the existing literature by providing insights on how the change of media ownership impacts the media bias in terms of the sentiment, length, and publication date of the articles.

\section{Hypotheses Development}

\subsection{Length}

The size allocation of an article is an indication of the value that a news outlet attributes to the story (Hamborg, Donnay \& Gipp, 2019). ${ }^{[20]}$ As long articles are expected to draw more attention than a short one (Bhowmick, Basu \& Mitra, $2009)^{[21]}$, the media frequently applies favoritism of specific topics and avoidance of others (Druckman \& Patrick, 2005) ${ }^{[22]}$. Consequently, by providing more information in the article, the media gets to raise the awareness of the readers and affect their perception of the story. Although measuring the length of the articles is a straightforward task, only a few studies measure the length bias of the media. Such includes research by Saez-Trumper et al. (2013), where a slight correlation between the importance of a story and length was found. ${ }^{[23]}$

Prior literature shows that the media has incentives to report profit-maximizing news and thus would dive more attention to negative events (Niessner \& So, 2017) ${ }^{[24]}$ and sensationalism that focus on critical corporate names, wellrecognized brands (Doyle, 2006) ${ }^{[25]}$. In our research, we assume that in reporting Amazon-related news, WP would have the incentive to please the owner. As such, we expect that WP would have a lengthier presentation of Good-for-Amazon articles compared to NYT. Consequently, our first hypothesis is as follows.

H1: The Washington Post reports lengthier articles on good news for Amazon, and shorter articles about bad news compared to the New York Times.

\subsection{Sentiment}

The connotation of an article is a subtle but impactful method of manipulating people's perception. From Bhowmick, Basu \& Mitra (2009), writing style could be affected by "labelling" and "word choice". ${ }^{[21]}$ Readers' reactions to each event or move highly dependent on the word choice by the author. Wordings used could pose a relatively positive (negative) signal for readers. By evaluating the emotional signals, one could interpret the bias on Amazon by the Washington Post in the post-acquisition period.

Thibodeau \& Boroditsky (2011) researched to prove that people are more inclined to perceive differently with different word choices, in their case, "metaphor" in news articles to ignite different sentiments in the reader. ${ }^{[26]}$ Their experiments showed that when people encounter "metaphor", they are not aware of how these words of metaphor have exerted influences on them. However, the metaphor often imposes a frame of how people interpret an issue, "by instantiating frame-consistent knowledge structures, and inviting structurally-consistent inferences... People like to think they are objective and making decisions based on numbers," Boroditsky said. "They want to believe they are logical. Nevertheless, they are being swayed by metaphors." (Gorlick, 2011). ${ }^{[27]}$ From the metaphor study on news articles and readers' reactions, it is understood the importance of word selection and how subtly it could affect readers' cognitive and sentiments without knowing.

Based on these studies above, we assume that the overall polarity of WP news will be more positive by stressing the positive news and down-playing on negative news, and our second hypothesis is expressed as follows:

H2: After the sale, the Washington Post reports good news about Amazon using more positive connotation and reports bad news about Amazon using less negative connotation compared to the New York Times. 


\subsection{Publication time}

The publication time is a significant dimension of news reporting that could influence the materiality or usefulness of the information provided to investors. Talking about the control of publication time of news, based on previous studies, we suppose that there are two main reasons. On the one hand, investors are probably interested in collecting timely information from companies they are involved in. Firms, therefore, react to pressures yielded from investors to disclose earnings more rapidly (Sengupta, 2014) ${ }^{[28]}$ On the other hand, organizations prefer news concerning earnings information to be released as rapidly as possible. Sengupta's research suggested that managers have the purpose of delaying the disclosure of negative news based on their examination of potential benefits as well as the costs of releasing earning information. By facilitating a favourable publication time of news, companies may better manage firm performance.

Qin, Strömberg, \& Wu (2018) examine the impact of market competition on political media bias through investigating the difference between media coverage of Chinese government-owned media and other local and worldwide public media. ${ }^{[29]}$ The general-interest newspapers were commonly named as Daily, Evening, and Metro according to editorial policies. Those newspapers vary in different publication time, i.e. "Metros" in the morning, whereas "Evening" in the afternoon. Despite that researchers did not distinctly illustrate whether different publication time of different newspapers directly affects political media bias, "Daily" is officially monitored by a government-regulated system, while "Metro" and "Evening" offer subsidiary newspapers that are more associated with the politics-oriented content and less controlled by the central departments. Accordingly, news publication time is highly possible to be an essential factor in dominating political media bias.

Interestingly, there is no study examining the reasons why the media differs publication time of news toward certain critical events in the field of financial journalism. However, based on our observation, newspapers tend to tilt news with controlling news publication time of financial news. It is worthy of researching whether the difference in news publication time is related to management's control of media coverage.

In the view of relatively limited previous work providing evidence on the link between publication time of news and control of media bias, we assume that the earlier news reporting one news is, the more useful information that is likely to boost the owner's profitability and earnings. Regarding the fact that Amazon directly owns WP, we thus assume that WP prefers to report good news such as disclosure of favourable information about owners quickly for improving financial results. Accordingly, we formulate the third hypothesis of our study as follows:

H3: The Washington Post reports bad Amazon-related news later than the New York Times, and good Amazon-related news earlier than the New York Times.

\section{Research design and data}

To measure the impact of Amazon ownership on WP coverage, we collect articles that have Amazon mentioning published by WP and NYT from the Factiva database. Our sample period begins on October 1, 2012, and ends on September 30, 2014, altogether 24 months, including 12 months before and 12 months after the buyout on October 1, 2013 (Fahri, 2013) ${ }^{[30]}$ By applying tools developed by Google Cloud AI \& Machine Learning, we extract all needed information in the table format, containing the headline, author, publication date, length (words/sentences), first sentence, sentiment score, and magnitude.

The sentiment score and magnitude are the numerical values representing the sentiment of the article (positive, neutral, or negative), which were tested using the sentiment analysis tool developed by Google. According to the research done by Google Research Team (2008) $)^{[31]}$, sentiment score (x) uses the following function:

$$
\text { Score } x=\sum_{t=1}^{n} s_{t}
$$

The score represents the individual score for a word within a text. The sentiment score ranges from -1.0 (negative) to +1.0 (positive), showing the overall emotional leaning of the text. Magnitude is the sum of without considering signs, ranging from 0.0 to +infinity. Thus, if the score is " 0.0 " it can mean two things. (1) If the magnitude is close to 0 , the text is neutral; (2) If the magnitude is large, then the text is mixed (positive and negative scores cancelled each other out). As such, a score closer to "+1.0" with high magnitude means that text is "clearly positive" and a score closer to "-1.0" with high magnitude means that text is "clearly negative".

For robustness, each article was then encrypted for the content of the news coverage, i.e. we read each article's headline and first sentence to identify the positivity of WP and NYT's reporting. The main event of the article can be described by five journalistic questions (who did what, when, where, and why), and can be answered by reading the first 
few sentences (Hamborg et al., 2018) ${ }^{[32]}$ Then, we filter out events that are reported by both newspapers. Afterwards, we form two groups of the articles - Good-for-Amazon articles and Bad-for-Amazon articles.

In our primary analysis, we use a difference-in-differences (DID) method to compare how WP and NYT reacted to identical circumstances over time. It is suitable because both WP and NYT compete for similar audiences on local and international levels, and have similar economic coverage.

This paper applies the DID method for two datasets (i.e. Good-for-Amazon articles and Bad-for-Amazon articles) separately. Each dataset includes one treatment group (i.e. WP's articles) and one control group (i.e. NYT's articles). We compare changes in NYT's reporting style unaffected by the pressure from Amazon's acquisition to the changes over time and WP's reporting style influenced by the acquisition intervention and attribute the "difference-in-differences" to the effect of the acquisition on newspapers' coverage. It provides us unbiased effect estimates if the trend over time would have been the same between the treatment and control groups in the absence of the intervention.

In our DID model, we assess the impact of the acquisition on WP's coverage by using our extracted data to compare how significant is the change in the way newspapers reported on Amazon along with several metrics: sentiment, length, and publication time. Any significant changes that we identify can be interpreted as due to the change in ownership. This means that both papers in the comparison are likely to change their coverage in response to the purchase of WP -- probably in response to the changing competitive landscape -- but the effect we identify is whether WP experienced an even more significant change by comparing with NYT.

\section{Empirical analysis}

Tables $1 \& 2$ show means of length, sentiment, and publication of Good-for-Amazon and Bad-for-Amazon articles published by WP and NYT across time. While Table 1 represents the aggregate mean differences of both papers before and after the acquisition, Table 2 contrasts the separate mean differences between two papers for the whole time period.

Table 1. Differences before and after acquisition

\begin{tabular}{ccccccc}
\hline & \multicolumn{2}{c}{ Good-for-Amazon articles by WP \& NYT } & \multicolumn{3}{c}{ Bad-for-Amazon articles by WP \& NYT } \\
\hline Variables & Pre-Acq & Post-Acq & Diff & Pre-Acq & Post-Acq & Diff \\
Length & 735.9 & 556.2 & $179.7 * * *$ & 666.9 & 652 & -0.0700 \\
Sentiment score & 0.0230 & 0.0410 & -0.0170 & -0.0440 & 0.0260 \\
Publication time & 2.8962 & 3.7079 & -0.8117 & 2.7983 & 7.7959 & -4.9976 \\
\hline
\end{tabular}

$t$ statistics in parentheses

$* p<0.1, * * p<0.05, * * * p<0.01$

From Table 1, it is evident that the length difference of the good-for-Amazon articles published by both papers has substantial change after the acquisition. The respective p-value is less than 0.01 , which indicates the significance of the difference at $1 \%$. While it is possible that some of the changes are due to the acquisition, it may not fully explain the variation identified. By way of comparison, if we look at Table 2, it is clear that the length difference of the good-for Amazon articles between individual papers has substantial change as well. The corresponding p-value is less than 0.05 , which indicates the significance of the difference at $5 \%$. Therefore, it is reasonable to assume that the acquisition has impacted WP's coverage in terms of length.

Table 2. Differences of good-for and bad-for Amazon articles

\begin{tabular}{ccccccc}
\hline & \multicolumn{3}{c}{ Good-for-Amazon articles } & \multicolumn{3}{c}{ Bad-for-Amazon articles } \\
\hline Variables & WP & NYT & Diff & WP & NYT & Diff \\
Length & 588.8 & 735.3 & $-146.517 * *$ & 670.6 & 628.7 & -0.95 \\
Sentiment score & 0.0410 & 0.0200 & 0.0210 & -0.0610 & -0.0520 & -0.0090 \\
Publication time & 2.7251 & 4.1931 & -1.4679 & 4.1578 & 4.2577 & -0.0998 \\
\hline
\end{tabular}

$t$ statistics in parentheses

$* p<0.1, * * p<0.05, * * * p<0.01$

On the other hand, the sentiment difference revealed different patterns - only minor changes took place after the acquisition and between individual newspapers, with corresponding p-value in both cases being greater than 0.1. However, from Table 2, we can see that WP reports good-for Amazon news more positively than NYT (0.0410 and 0.0200 , respectively), and reports bad-for Amazon news more negatively than NYT (-0.0610 and -0.0520 , respectively). 
Apparently, given the nature of sentiment (sum of single words' scores ranging from -1.0 to +1.0 ), WP seems to be more emotional in reporting Amazon related news compared to NYT.

As Table 1 shows, the publication time difference of the Bad-for-Amazon articles has a significant change (-4.9976) with p-value $<0.05$. This could possibly imply that WP published Bad-for-Amazon articles later than NYT. However, the publication time difference has no significant changes for Good-for-Amazon articles $(-0.8117, \mathrm{p}$ value $>0.1)$.

To characterise the change more thoroughly and better control for the possible unobservable factors, we apply double difference regression models to model the differences in length, sentiment, and publication time between the NYT and WP, using an indicator for the time after the acquisition Bezos and an indicator of the possible difference between the WP and NYT before the acquisition Graham. Specifically, our regression form is:

$$
\left(W P_{t}-N Y T_{t}\right)=\beta_{0}+\beta_{1} * \text { Bezos }+\beta_{2} * G r a h m+\delta_{t}
$$

where $W P_{t}-N Y T_{\mathrm{t}}$ are the mean differences in length or sentiment or publication time in time period $\mathrm{t}, \beta_{0}$ is the baseline average difference between WP and NYT, $\beta_{1}$ is change in that difference after acquisition, $\beta_{2}$ is the difference between the NYT and WP pre-intervention, and $\delta_{\mathrm{t}}$ is the event matching effects to control for the disparity in Amazon-related articles and remove confounders. The positive $\beta$ value indicates an increase in length or sentiment of the Amazon-related articles and negative $\beta$ value means the vice versa.

For reference, Table 3 represents the differences in length, sentiment, and publication time of Good-for-Amazon and Bad-for-Amazon articles before and after the acquisition.

Table 3. Differences in length, publication time and sentiment

\begin{tabular}{|c|c|c|c|}
\hline \multirow{2}{*}{ Good-for-Amazon articles } & Length & Sentiment & Publication time \\
\hline & (1) & (2) & (3) \\
\hline WP - NYT & -193.6 & -0.00888 & 6.2920 \\
\hline (Std. Err.) & (129.82) & $(-0.029)$ & $(26.75)$ \\
\hline \multirow[t]{2}{*}{ Bezos } & -76.09 & 0.0211 & -0.9009 \\
\hline & $(-0.87)$ & $(0.92)$ & $(1.47)$ \\
\hline \multirow[t]{2}{*}{ Graham } & $217.1 * *$ & -0.0165 & -1.0358 \\
\hline & $(2.34)$ & $(-0.85)$ & $(1.31)$ \\
\hline \multirow[t]{2}{*}{ Intercept } & $620.8 * * *$ & $0.0323 *$ & $3.2786^{* * *}$ \\
\hline & $(9.89)$ & (1.93) & $(0.95)$ \\
\hline \multirow[t]{2}{*}{$\mathrm{N}$} & 220 & 220 & 220 \\
\hline & 0.0638 & 0.0159 & 0.0361 \\
\hline \multirow{2}{*}{ Bad-for-Amazon Articles } & Length & Sentiment & Publication Time \\
\hline & (1) & (2) & (3) \\
\hline WP-NYT & 166.904 & $-0.0879 * *$ & -5.7070 \\
\hline (Std. Err.) & $(143.71)$ & $(0.038)$ & $(25.46)$ \\
\hline \multirow[t]{2}{*}{ Bezos } & -64.03 & -0.0003 & -2.6534 \\
\hline & $(-0.78)$ & $(-0.02)$ & $(2.54)$ \\
\hline \multirow[t]{2}{*}{ Graham } & $-133.6^{*}$ & $0.0568 * *$ & -0.4781 \\
\hline & $(-1.76)$ & $(2.46)$ & $(3.55)$ \\
\hline \multirow[t]{2}{*}{ Intercept } & $706.8 * * *$ & $-0.0611 * * *$ & $4.2962 * *$ \\
\hline & (11.62) & $(-4.25)$ & (1.91) \\
\hline $\mathrm{N}$ & 174 & 174 & 174 \\
\hline$R^{2}$ & 0.0102 & 0.0445 & 0.0492 \\
\hline
\end{tabular}

$t$ statistics in parentheses

$* p<0.1, * * p<0.05, * * * p<0.01$

In contrast with the patterns evident in Table $1 \&$ Table 2 , the first column of Table 3 reveals that the length difference of the Amazon related articles did not significantly change following the acquisition. The results, contrary to our hypothesis (H1), suggest that length of Good-for-Amazon articles became shorter and length of Bad-for-Amazon articles became 
longer post-acquisition.

Following the trend, the results reported in the second column of Table 3 indicated that the sentiment difference of Good-for-Amazon articles has no significant change as well. In contrast, the sentiment difference of Bad-for-Amazon articles has significant change with p-value significant at 5\%. The sentiment difference derived from Bad-for-Amazon articles seems to follow the patterns revealed in Table 2, whereas the sentiment difference derived from Good-for-Amazon articles suggest the opposite.

The results in the third column reveal that the publication time difference has insignificant changes for both Goodfor-Amazon and Bad-for-Amazon articles, $p$ value $>0.1$. However, the difference value of publication time itself does not provide any insights. Because publication time difference is the mean of (reporting date - acquisition date), positive value of the WP-NYT for articles before acquisition means WP reports earlier than NYT, and for articles after acquisition means WP reports later than NYT. Thus, results obtained confirm our hypothesis H3 because the value of WP-NYT is negative for both before \& after acquisition for Good-for-Amazon articles, -47.064 and -40.772, respectively (Appendix B).

\section{Discussion}

Our empirical test results show that ownership change at WP has significant influence on publication date of Amazon-related articles compared to NYT. For length and sentiment of the articles, the existing results do not show much correlation with the ownership change. We revised literature review and proposed following concerns in enhancing the research outcome:

\subsection{Length}

The empirical test results show that the acquisition has no significant impact on the length difference between the NYT and WP. In contrast, the existing literature has shown that the size allocation of the article indicates the value media assigns to the story (Bhowmick, Basu \& Mitra, 2009) ${ }^{[21]}$, and accordingly, a significant change in the length difference of the Amazon-related articles was expected as Bezos encouraged WP to cover him and Amazon aggressively (Meyer, 2014) ${ }^{[3]}$.

Both the nature of the event (good/bad) and scale (big/small) impact the attention given to the article, but we did not include the scale of the event in our regression model. To address this limitation we test matching articles written on the same events. In the double-difference regression, we need to test what is the pattern of changes in length difference between Good-for-Amazon and Bad-for-Amazon articles. Druckman \& Parkin (2005) have discovered that news outlets report disproportionally much on one topic. ${ }^{[22]}$ Bhowmick, Basu \& Mitra (2009) ${ }^{[21]}$ also claimed that longer stories grab more attention. Thus, to accept our hypothesis, the length difference should be positive for Good-for-Amazon articles and negative for Bad-for-Amazon articles. Since the empirical analysis results suggest that after the acquisition the length difference of Good-for-Amazon is negative (-193.6) and positive (166.9) for Bad-for-Amazon articles, and the significance level is low, the hypothesis is rejected. WP does not report longer articles on news that are good for Amazon or shorter articles on news that are bad for Amazon.

One major concern with the results is the potential discrepancy of the data. Given that we identify and match articles based on headline \& first sentence, there is a possibility of overlooking important articles and/or including articles that contain the digest of different news that adversely affected the robustness of the results. Since our research focuses on articles published online, future study could incorporate the placement of article and size of preview on main and other web-pages (Hamborg, Donnay \& Gipp, 2019). ${ }^{[20]}$ In that way, more systematic and comprehensive analysis can be produced.

\subsection{Sentiment}

The result has demonstrated media ownership poses no significant impact on the reporting sentiment of the owner. The results of DID analysis on sentiment score (See Appendix A) has shown that WP reported Good-for-Amazon articles less positively than NYT in both the pre-acquisition (-0.017) and the post-acquisition (-0.025) periods. For Bad-forAmazon articles, WP has reported them less negatively than NYT in the pre-acquisition (0.057) period and more negatively in the post-acquisition (-0.031) period. With DID eliminating the unrelated factors, the effect caused by the acquisition is deduced to be -0.00888 and -0.0879 respectively representing a low significance level for Good-for-Amazon and Bad-forAmazon articles. Meanwhile, literature review suggested that the media frequently frames the subjects/events with various predetermined words to manipulate our perceptions (Parenti, 1997). ${ }^{[2]}$ Thibodeau \& Boroditsky (2011) even showed that bias would be pervasive in the media as different word sets are adopted by various media. ${ }^{[2]}$ This idea was further evidenced by Arthur Hays, owner of NYT, who would send notes with instructions, suggestions, complaints and orders to NYT editor Turner Catledge (Chomsky, 2006) regarding news that ranges from being directly related to the owner to 
personal preferences. ${ }^{[11]}$ The empirical results oppose our assumptions and suggest that the sentiment difference is negative and minor, and thus, the hypothesis $\mathrm{H} 2$ is refuted.

Nonetheless, we consider that results are inconsistent with literature review due to the faults in the sentiment analysis tool. Since the machine assigns sentiment score to every single word and then sums them together to get the mean, the negative words dedicated to other companies or people could possibly cancel out the effect of positive words used to describe Amazon. Thereby, showing a higher negativity in the articles which have mentioned Amazon positively. Another limitation of the sentiment score is the inability to distinguish emotions. For example, when the article described Amazon to be angry or sad, the machine would have recognized the article negatively, yet, it does not mean the article is reporting negatively on Amazon, the post might still be supportive towards Amazon. It is the same for sarcastic sentences as well. Therefore, we recommend future study to improvise on the sentimental data collection by applying more comprehensive AI word processing tools.

\subsection{Publication time}

Based on the empirical results, we can identify the acquisition has significant influence on the publication time difference between NYT and WP. Prior studies have indicated that the publication time could influence materiality of the information provided to investors. Kothari, Li, \& Short (2009) claimed that management might delay the publication of bad-for-company news for uncertainty-increasing content. ${ }^{[33]}$ We have provided a directional solution to predict timeliness of favorable and unfavorable news.

According to the empirical analysis, the publication time difference of Good-for-Amazon articles is -47.064 before acquisition and -40.772 after the acquisition, both significant at 5\% (Appendix B). This implies that WP reported Goodfor-Amazon articles later than NYT before the acquisition, and earlier after the acquisition, which is consistent with our hypothesis H3. Regarding Bad-for-Amazon articles, the empirical analysis revealed that the publication time difference of articles is -11.873 before acquisition and -5.707 after the acquisition, but results are not significant (Appendix B). It indicates that WP and NYT publish news around the same time. This result is reasonable as the media bias is often expressed through the omission of the bad news and/or facts (Anderson \& McLaren, 2012). ${ }^{[19]}$ Thus, the hypothesis H3 is accepted.

One limitation of our study is that we only use 24 months' data. The study of a more extended period could provide more robust results, which may be predicted to generate a wider range of situational and organizational variation. We also recommend using higher-quality quantitative methods of data analysis to calculate the publication time difference. Besides, we have marked 66 significant events through the matching of all articles. Future research can perform sub-analysis to excavate more profoundly into question whether the acquisition had a different or similar effect on the publication time between papers. This would be helpful for future studies to focus more on how different papers respond to relevant events with the impact of media manipulation.

\subsection{Further research on media ownership}

Future research on media ownership and bias may explore how media manipulation impacts the company's stock market performance because this will help us better understand the effects of such coverage on the public. Plenty of exemplary investigations have shown the significant impact of media on capital markets. In terms of the general correlation between media reporting and firm's performance, Tetlock (2007) found that great amounts of media pessimism cause descending pressure on market prices. ${ }^{[34]}$ His study provided evidence on the actual effect of the WSJ publicizing U.S. stock market returns. Another study by Huberman \& Regev (2001) showed that when the old article on ENMD's cancer research breakthrough was published by NYT, it caused a dramatic increase in stock prices of ENMD and other biotechnological companies in the same industry, which was more significant than the effect of this article when it was reported five months ago in Times and Nature. ${ }^{[35]}$

There are more questions remaining in the field of media ownership and bias such as what are the consequences faced by those journalists that report biased news, e.g. career promotion, higher pay, dismissal, prosecution, and etc. As such, measuring the journalist's incentive could provide insights on hidden conflicts within the organization (Turow, 1994) and extend the findings on media ownership and bias. ${ }^{[17]}$

\section{Conclusion}

This research aims at investigating the relationship between changing media ownership and the bias in media coverage. We found that change in the ownership at WP correlates with the changes in news reporting, namely, in the length, sentiment, and publication time of the articles. Based on the results of the empirical study, we conclude that 
Amazon's acquisition has a favourable impact on the publication time of articles and a relatively small impact on sentiment and length, however, the results are not robust.

This paper was an attempt to deal with the area of research that had little attention previously. Although our results are modest, they do guide further study with constructive headers and a deeper understanding of the role of the media for entrepreneurs. We conclude by remarking that influence by media ownership is present and media, as an essential outlet for the information dissemination, will remain to be a potential tool for companies or the government, as an owner, to manipulate the public's perception.

\section{References}

[1] Kanjo W. (2017). What the media won't tell you about the war in Syria: Essays. Place of publication: not identified; Publisher: not identified.

[2] Parenti M. Methods of media manipulation. The Humanist. 1997; 57(4): 5.

[3] Meyer M. (2014, July-August). Brick by brick. Columbia Journalism Review. Available from: https://archives.cjr.org/ cover_story/washington_post_jeff_bezos.php.

[4] Exploring the Amazon. The Economist. 2015; 415: 64

[5] Day M., Metcalf T. (2019, July 6). MacKenzie Bezos Gets Ready for a \$38 Billion Stake in Amazon. Bloomberg. Retrieved from: https://www.bloomberg.com/news/articles/2019-07-05/bezos-split-finalizes-as-38-billion-amazon-staketransfer-looms.

[6] Stewart J. (2019, January 21).Why Jeff Bezos' Divorce Should Worry Amazon Investors. The New York Times. Retrieved from Factiva database.

[7] Jeff Bezos, in divorce settlement, retains 75 percent of the couple's Amazon stock and all voting power (2019, April 4). The Washington Post. Retrieved from Factiva database.

[8] Inquiring minds: How did a tabloid get Jeff Bezos's texts? (2019, February 6). The Washington Post. Retrieved from Factiva database.

[9] Archer A. M., Clinton J. Changing Owners, Changing Content: Does Who Owns the News Matter for the News? Political Communication. 2018; 35(3): 353-370.

[10] Lutz A. (2012) These 6 Corporations Control 90\% of The Media In America. Business Insider. Available from: https:// www.businessinsider.com/these-6-corporations-control-90-of-the-media-in-america-2012-6.

[11] Chomsky D. "An Interested Reader": Measuring Ownership Control at the New York Times. Critical Studies in Media Communication. 2006; 23(1): 1-18.

[12] Harding J. (2002, June 11). Media king warms to his subjects. Financial Times. p. 30.

[13] Szalai G. (2007, January 27). Murdoch: Big media has less sway on Internet. The Hollywood Reporter.

[14] Bagdikian B. H. The Media Monopoly (4th ed.). Boston: Beacon Press; 1992.

[15] Gilens M., Hertzman C. Corporate Ownership and News Bias: Newspaper Coverage of the 1996 Telecommunications Act. The Journal of Politics. 2000; 62(2): 369-386.

[16] Hanretty C. Media outlets and their moguls: Why concentrated individual or family ownership is bad for editorial independence. European Journal of Communication. 2014; 29(3): 335-350.

[17] Turow, J. Hidden Conflicts and Journalistic Norms: The Case of Self-Coverage. Journal of Communication. 1994; 44(2): 29-46.

[18] Butler A. W., Gurun U. G. Don’t Believe the Hype: Local Media Slant, Local Advertising, and Firm Value. The Journal of Finance. 2012: 67(2): 561-598.

[19] Anderson S. P., McLaren J. Media Mergers and Media Bias with Rational Consumers. Journal of the European Economic Association. 2012; 10(4): 831-859.

[20] Hamborg F., Donnay K., Gipp B. Automated identification of media bias in news articles: an interdisciplinary literature review. International Journal on Digital Libraries. 2019; (20): 391-415.

[21] Bhowmick P. K., Basu A., Mitra P. Reader Perspective Emotion Analysis in Text through Ensemble-based Multi-Label Classification Framework. Computer and Information Science. 2009; 2(4): 64-74.

[22] Druckman J. N., Parkin M. The impact of media bias: how editorial slant affects voters. J. Polit. 2005; 67(4): 10301049.

[23] Saez-Trumper D., Castillo C., Lalmas M. (2013, October). Social media news communities: gatekeeping, coverage, and statement bias. In Proceedings of the 22nd ACM International Conference on Information \& Knowledge Management (pp. 1679-1684).

[24] Niessner M., So E. (2017) Bad News Bearers: The Negative Tilt of Financial Press. Social Science Research Network.

[25] Doyle G. Financial news journalism: A post-Enron analysis of approaches towards economic and financial news pro- 
duction in the UK. SAGE Publications. 2006; 7(4): 433-452.

[26] Thibodeau P. H., Boroditsky L. Metaphors we think with: The role of metaphor in reasoning. PloS one. 2011; 6(2): e16782.

[27] Gorlick A. (2011, Feb 23) Is crime a virus or a beast? When describing crime, Stanford study shows the word you pick can frame the debate on how to fight it. Stanford News. Available from: https://news.stanford.edu/news/2011/february/metaphors-crime-study-022311.html.

[28] Sengupta P. Disclosure timing: Determinants of quarterly earnings release dates. Journal of Accounting and Public Policy. 2004; 23(6): 457-482.

[29] Qin B., Strömberg D., Wu Y. Media bias in China. American Economic Review. 2018; 108(9): 2442-76.

[30] Fahri P. (2013, Oct 1) The Washington Post Closes Sale to Amazon Founder Jeff Bezos. The Washington Post. Available from: https:/www.washingtonpost.com/business/economy/washington-post-closes-sale-to-amazon-founder-jeffbezos/2013/10/01/fca3b16a-2acf-11e3-97a3-ff2758228523_story.html.

[31] Google Research Team: Blair-Goldensohn S., Neylon T., Hannan K., Reis G. A., McDonald R., Reynar J. (2008) Building a Sentiment Summarizer for Local Service Reviews. Google. Available from: https://research.google/pubs/ pub34368/.

[32] Hamborg F., Lachnit S., Schubotz M., Hepp T., Gipp B. (2018) Giveme5W: Main Event Retrieval from News Articles by Extraction of the Five Journalistic W Questions. In: Proceedings of the iConference.

[33] Kothari S. P., Li X., Short J. E. The effect of disclosures by management, analysts, and business press on cost of capital, return volatility, and analyst forecasts: A study using content analysis. The Accounting Review. 2009; 84(5): 16391670 .

[34] Tetlock P. C. Giving Content to Investor Sentiment: The Role of Media in Stock Market. The Journal of Finance. 2007; 62(3): 1139-1168.

[35] Huberman G., Regev T. Contagious Speculation and a Cure for Cancer: A Nonevent that Made Stock Prices Soar. The Journal of Finance. 2001; 56(1): 387-396. 


\section{Appendix A}

DID of sentiment — Good-for-Amazon articles

DIFFERENCE-IN-DIFERRENCES ESTIMATION RESULTS

\begin{tabular}{cccc}
\hline Number of observations in the DIPF-IN-DIFF: 220 \\
Before & Arter & \\
Control: & 62 & 45 & 107 \\
Treated: & 70 & 43 & 113 \\
& 132 & 88 &
\end{tabular}

\begin{tabular}{|c|c|c|c|c|}
\hline Ouccore var. & $\operatorname{sen} t i=t$ & S. Brr. & $|t|$ & $P>|c|$ \\
\hline \multicolumn{5}{|l|}{ Before } \\
\hline Control & 0.032 & & & \\
\hline Treated & 0.016 & & & \\
\hline Diff $(\mathrm{T}-\mathrm{C})$ & -0.017 & 0.018 & -0.89 & 0.372 \\
\hline \multicolumn{5}{|l|}{ Arcer } \\
\hline Control & 0.053 & & & \\
\hline Ireated & 0.028 & & & \\
\hline Diff $(T-C)$ & -0.025 & 0.023 & 1.12 & 0.262 \\
\hline Diff-in-Diff & -0.009 & 0.029 & 0.30 & 0.761 \\
\hline
\end{tabular}

R-square: 0.02

- Means and Scandard Errors are estimated by linear regression

*Inference; ** $p<0.01 ; *$ D $<0.05 ; * D<0.1$

DID of sentiment — Bad-for-Amazon articles

DIPPERENCE-IN-DIPPERENCES RSTIMATION RBSOLTS

Number of observations in the DIFF-IN-DIFF: 174

$\begin{array}{clll} & \text { Before } & \text { After } & \\ \text { Control: } & 54 & 70 & 124 \\ \text { Treated: } & 23 & 27 & 50 \\ & 77 & 97 & \end{array}$

\begin{tabular}{|c|c|c|c|c|}
\hline Outcome var. & $\operatorname{sen} t 1 \sim t$ & S. $\mathbf{E} x y$. & $|\tau|$ & $P>|\tau|$ \\
\hline \multicolumn{5}{|l|}{ Berore } \\
\hline Control & -0.061 & & & \\
\hline Treated & -0.004 & & & \\
\hline Diff $(T-C)$ & 0.057 & 0.028 & 2.03 & $0.044 * k$ \\
\hline \multicolumn{5}{|l|}{ After } \\
\hline Control & -0.061 & & & \\
\hline Ireated & -0.093 & & & \\
\hline Diff $(T-C)$ & -0.031 & 0.025 & 1.23 & 0.222 \\
\hline Diff-in-Diff & -0.088 & 0.038 & 2.33 & $0.021 \star \star$ \\
\hline
\end{tabular}

R-square: $\quad 0.04$

* Means and Standard Errors are estimated by linear regression

*Inference: *** p<0.01; ** p<0.05; * p<0.1 


\section{Appendix B}

\begin{tabular}{l|l|l|l|l}
\multicolumn{5}{c}{ DID of publication time - Good-for-Amazon articles } \\
\hline Outcome var. & time0 & S. Err. & $|t|$ & $\mathrm{P}>|\mathrm{t}|$ \\
\hline $\begin{array}{l}\text { Before } \\
\text { Control }\end{array}$ & $\begin{array}{l}139.306 \\
\text { Treated }\end{array}$ & & & \\
$\quad \begin{array}{l}\text { Diff (T-C) } \\
\text { After }\end{array}$ & -47.064 & 16.937 & -2.78 & $0.006 \star \star$ \\
$\quad \begin{array}{l}\text { Control } \\
\text { Treated } \\
\text { Diff (T-C) }\end{array}$ & $\begin{array}{l}264.400 \\
223.628\end{array}$ & & & \\
& -40.772 & 20.711 & 1.97 & $0.050 \star$ \\
Diff-in-Diff & 6.292 & 26.754 & 0.24 & 0.814 \\
\hline
\end{tabular}

\begin{tabular}{l|l|l|l|l}
\multicolumn{5}{c}{ DID of publication time - Bad-for-Amazon articles } \\
\hline Outcome var. & time0 & S. Err. & $|t|$ & P $>|t|$ \\
\hline $\begin{array}{l}\text { Before } \\
\text { Control }\end{array}$ & 198.481 & & & \\
$\quad \begin{array}{l}\text { Treated } \\
\text { Diff (T-C) }\end{array}$ & $\begin{array}{l}186.609 \\
-11.873\end{array}$ & 18.834 & -0.63 & 0.529 \\
After & 272.357 & & & \\
$\quad \begin{array}{l}\text { Control } \\
\text { Treated } \\
\text { Diff (T-C) }\end{array}$ & -17.579 & 17.136 & 1.03 & 0.306 \\
& & & & \\
Diff-in-Diff & -5.707 & 25.463 & 0.22 & 0.823 \\
\hline
\end{tabular}

Remarks: Control - NYT; Treated - WP 